\title{
Development Priorities and Key Challenges of Automation and Robotics in High-Rise Building Construction
}

\author{
Shiyao Cai ${ }^{\mathrm{a}}$, Zhiliang Ma* ${ }^{\mathrm{a} *}$, Miroslaw J. Skibniewski ${ }^{\mathrm{b}}$, Song $\mathrm{Bao}^{\mathrm{c}}$ \\ ${ }^{a}$ Tsinghua University, Qinghuayuan 1 Haididan District, Beijing 100084, China \\ ${ }^{b}$ University of Maryland, College Park, 1188 Glenn L. Martin Hall, College Park, MD 20742-3021, United States \\ ${ }^{c}$ Glodon Company Limited, Xibeiwang East Road Haidian District, Beijing 100193, China
}

\begin{abstract}
The construction industry is facing the challenges of low productivity, poor working environment, safety problems, an aging workforce. Particularly in high-rise building construction, these problems are serious because of the larger labor demand and a more dangerous working environment. Automation and robotics are expected to provide solutions to these problems while the level of application in the construction industry is still very low. This study identified development priorities (DPs) and key challenges (KCs) of automation and robotics in high-rise building construction through a questionnaire survey and an international expert workshop. Based on literature review and brainstorming, preliminary needs and influential factors were identified and a questionnaire was designed. The questionnaire survey was then conducted among senior engineers from major construction companies in China, evaluating the needs and influential factors related to robotics implementation. Based the results of the survey, an international workshop was held to furtherly identify DPs and KCs. This paper presents the processes and results of both the questionnaire survey and the workshop, identified and analyzed the DPs and KCs, and makes suggestions for future approaches to applying automation and robotics in high-rise building construction.
\end{abstract}

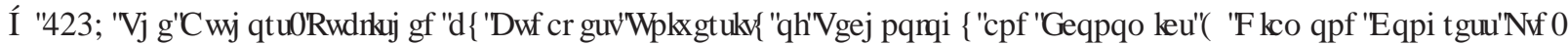

Peer-review under responsibility of the scientific committee of the Creative Construction Conference 2019.

Keywords: automation and robotics; development priority; high-rise building construction; key challenge

\section{Introduction}

Low productivity, poor working environment and safety problems are still enduring concerns at construction sites. Also, as the problem of aging becomes more and more serious, the labor costs of on-site construction are growing rapidly. The increasing number of the world's high-rise buildings exacerbates these problems because it requires a larger quantity of labor force and working in high elevation leads to safety risks. As conventional construction methods have reached their limits to meet the growing need of the construction industry [1], automation and robotics are expected to replace on-site human labor and improve productivity and quality. A number of studies on construction automation and robotics emerged since the 1980s, developing various types of systems and technologies with successful practical applications in construction projects or even commercial products. Based on the results of these studies, researchers made efforts to encourage the adoption and implementation based on ergonomic and economic analysis, application decision-making frameworks and identification of barriers [2-5]. However, the application of 
automation and robotics at the construction sites remains limited and the right approach to promote it in mid-2 $1^{\text {st }}$ century is still unclear.

Therefore, this paper aims to focus on high-rise building construction and seek answers to the above problem by investigating development priorities (DPs) and key challenges (KCs) with a questionnaire survey and an international expert workshop. It is believed that the results would be helpful for both academia and industry to decide on the future development of automation and robotics in high-rise building construction. The remainder of this paper is organized as follows. In Section 2, the research method is introduced. Section 3 presents the questionnaire survey as well as the preparation based on literature review and brainstorming, and Section 4 describes the process and analyses the results of the workshop. Section 5 summarizes the findings and proposes suggestions for future research and application.

\section{Method}

In terms of construction automation and robotics, three main parties are directly involved, i.e., researchers, robot or other automated equipment developers (hereinafter referred to as robot developers), and construction companies. Generally, researchers conduct basic research on knowledge and technologies; robot developers produce robots based on the research results; construction companies make use of the robots for practical application. Duties of the three parties are sometimes partially overlapping. For example, some robot developers conduct research independently and some construction companies can develop robots or automation equipment by themselves.

Therefore, the identification of DPs and KCs of automation and robotics in high-rise building construction requires participation and joint efforts of all three parties. With regard to DPs, both the market needs and the technical feasibilities should be considered. The needs could be distinguished by construction engineers with rich on-site experience, while the technical feasibilities could be judged by researchers and robot developers. As for identification of KCs, face-to-face discussion is needed because each party has its challenges, affected by multiple influential factors.

According to the above analysis, a mixed research method was used in this study, as shown in Fig. 1. This method includes a questionnaire survey towards construction companies to get a general picture of the needs and influential factors from the perspective of construction practices, and an international expert workshop for discussions among all parties. Since it is hard for construction engineers to come up with their own ideas on needs and influential factors in a questionnaire survey, we prepared preliminary lists of needs and influential factors based on literature review and brainstorming, and requested the engineers to evaluate their significances.

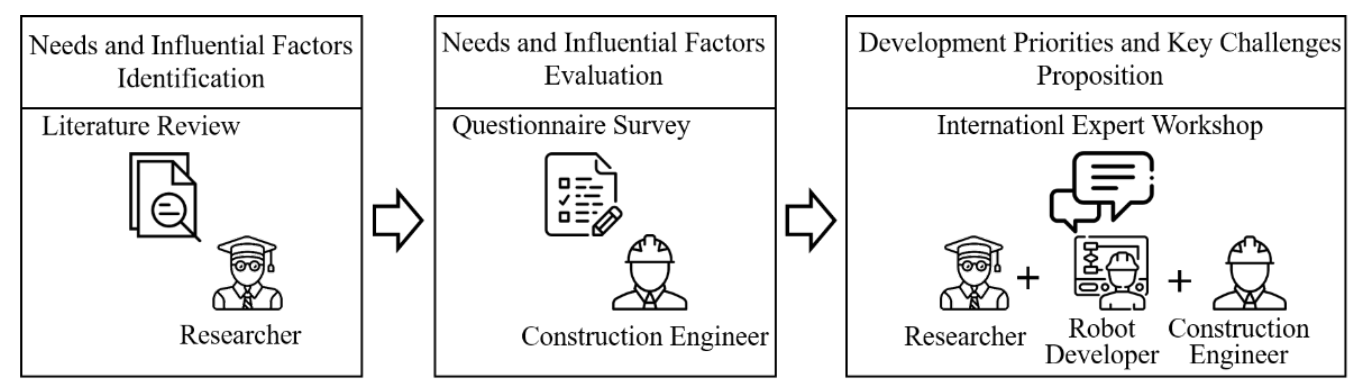

Fig. 1. Overview of research method.

\section{Needs and influential factors of applying automation and robotics in high-rise building construction}

\subsection{Preliminary identification based on literature review and brainstorming}

The preliminary identification of needs and influential factors was carried out by literature review and brainstorming. According to Standard of Construction Classification (GB/T 50840-2013), a national construction standard in China, building construction work can be classified into several categories, including earth and foundation, superstructure, decoration, etc. Considering the features of high-rise buildings and referring to existing reviews on construction 
Shiyao Cai, et al./ Proceedings of the Creative Construction Conference (2019) 007

https://doi.org/10.3311/CCC2019-007

automation and robotics [6-9], we brainstormed possible needs in each category. For influential factors, the themes of reviewed studies are not only limited to construction automation and robotics but also include the application of other information technologies, such as BIM, because they are considered to have common traits and tend to be influenced by similar factors. Table 1 and Table 2 respectively show the identified needs and influential factors. The columns of mean and rank present the results of the following questionnaire survey, which are illustrated in Section 4.

Table 1. Preliminary needs \& evaluation results of the questionnaire survey

\begin{tabular}{lccccc}
\hline \multicolumn{1}{c}{ Needs } & Mean & Rank & \multicolumn{1}{c}{ Needs } & Mean & Rank \\
\hline 1. Earth moving & 3.26 & 18 & $* 11$. External wall painting & 3.67 & 9 \\
2. Horizontal site logistics of materials and equipment & 3.54 & 12 & 12. Floor tiling & 3.53 & 14 \\
*3. Vertical site logistics of materials and equipment & 3.85 & 5 & 13. Concrete finishing & 3.54 & 13 \\
*4. Steel welding & 4.36 & 1 & 14. Ceiling installation & 3.25 & 19 \\
*5. Steel assembly & 3.67 & 9 & 15. Partition wall installation & 3.29 & 17 \\
*6. Steel coating & 3.98 & 3 & 16. Door and window installation & 3.15 & 20 \\
*7. Monitoring of the deformation and internal force of & 4.29 & 2 & 17. Material quality inspection & 3.52 & 15 \\
the steel structure & 3.81 & 6 & $* 18$. Construction quality inspection & 3.78 & 7 \\
*8. Prefabricated component assembly & 3.65 & 11 & $* 19$. Monitoring of construction equipment & 3.74 & 8 \\
9. Curtain wall installation & 3.45 & 16 & $* 20$. Protection of work performed overhead & 3.89 & 4 \\
10. Façade tile installation & & &
\end{tabular}

Table 2. Preliminary influential factors \& evaluation results of the questionnaire survey

\begin{tabular}{|c|c|c|c|c|c|c|c|}
\hline Influential factor & References & Mean & Rank & Influential factor & References & Mean & Rank \\
\hline *1. Labor cost of construction & {$[1,10]$} & 3.82 & 9 & 12. Policy on environmental impacts of & [15] & 3.61 & 20 \\
\hline *2. Initial investment cost of automation and & {$[5,11]$} & 4.41 & 1 & & & & \\
\hline robotics technology & & & & $\begin{array}{l}\text { 13. Globalization in construction (new } \\
\text { technologies, foreign labor, etc.) }\end{array}$ & [16] & 3.30 & 21 \\
\hline automation and robotics & [10-12] & 3.94 & 4 & *14. Governmental support on academic & & & \\
\hline $\begin{array}{l}\text { * } 4 \text {. Maturity and proven technology to provide } \\
\text { robust performance and ease of use }\end{array}$ & {$[1,5]$} & 4.19 & 2 & $\begin{array}{l}\text { research of construction automation and } \\
\text { robotics }\end{array}$ & {$[11,15,16]$} & 3.87 & 7 \\
\hline $\begin{array}{l}\text { 5. Mature skill training to acquire new } \\
\text { technologies }\end{array}$ & {$[12,13]$} & 3.65 & 19 & $\begin{array}{l}\text { *15. Governmental support on automation } \\
\text { and robotics application in construction }\end{array}$ & {$[11,16]$} & 3.91 & 6 \\
\hline 6. Adaption to the traditional construction method & {$[1,12]$} & 3.71 & 16 & 16. Culture of innovation & {$[5,16]$} & 3.78 & 12 \\
\hline 7. Attention to new technologies in the industry & [14] & 3.73 & 13 & 17. Public awareness of environmental & {$[12,15]$} & 3.80 & 11 \\
\hline $\begin{array}{l}\text { 8. Research and development capability of } \\
\text { construction companies }\end{array}$ & & 3.70 & 17 & & & & \\
\hline *9. Application of other information technologies & {$[14,15]$} & 3.95 & 3 & $\begin{array}{l}\text { *18. Social attention to occupational safety } \\
\& \text { health }\end{array}$ & {$[10,11]$} & 3.86 & 8 \\
\hline $\begin{array}{l}\text { (BIM, lo T, etc.) } \\
\text { 10. Labor policy }\end{array}$ & {$[15,16]$} & 3.71 & 15 & $\begin{array}{l}\text { *19. Age structure and education of the } \\
\text { workforce }\end{array}$ & {$[1,11]$} & 3.82 & 9 \\
\hline \multirow{2}{*}{$\begin{array}{l}\text { 11. Government policy on time limit for the } \\
\text { projects }\end{array}$} & & \multirow{2}{*}{3.69} & \multirow{2}{*}{18} & 20. The scale of prefabrication & [17] & 3.72 & 14 \\
\hline & & & & $* 21$. The ability of on-site management & {$[11,12]$} & 3.94 & 4 \\
\hline
\end{tabular}

\subsection{Evaluation based on a questionnaire survey}

An online questionnaire was adopted, which included four sections. The first section is a brief introductory letter presented the research objectives and the author's contact details. The second section solicited the profiles of the respondents and their organizations. In the third and fourth sections, the preliminary needs and influencing factors identified above were listed respectively. The respondents were requested to rate the level of significance of the needs and influencing factors with five-point Likert scales (rate from 1-5, 1 for very insignificant, and 5 for very significant). 
Shiyao Cai, et al./ Proceedings of the Creative Construction Conference (2019) 007

https://doi.org/10.3311/CCC2019-007

On selection of potential respondents, we focused on senior engineers from recognized construction companies, because these companies tend to have adequate resources for implementation of automation and robotics. We sent the link of the questionnaire through emails and messages to those in the expert databases of China Construction Industry Association (CCIA) and China Civil Engineering Society (CCES), which include experts from the most recognized construction companies in China. Survey responses were collected in three months, from June to August 2018. During this period, 795 questionnaires were sent out, and 108 valid ones were obtained, with a response rate of $13.6 \%$.

Table 3 shows the profiles of the respondents and their companies. The distribution of respondents' positions and work experience indicated that they have high expertise in construction and their opinions would have significant effects on the future development of their companies. The responding companies covered different scales (small 14.8\%, medium 42.6\%, and large 42.6\%) and were distributed in different areas throughout the country (East China 37.0\%, North China 26.9\%, South China 15.7\%, Central China 7.4\%, NorthEast China 5.6\%, NorthWest China 3.7\%, and SouthWest China 3.7\%). According to the qualification standard for construction companies in China, most responding companies had super grades or first grades of qualifications in general contractor $(92.6 \%)$, steel structure works $(69.4 \%)$, decoration works $(67.6 \%)$, earth and foundation work $(63.0 \%)$, etc., which suggested their high professional construction abilities. Among the responding companies, $94.4 \%$ had experience of applying BIM, and a considerable amount of them had applied IoT, big data, AI, and automation and robotics, which indicated their positive attitude of embracing new technologies in construction. Thus, the responding companies are considered to represent the key potential users of construction automation and robotics in China. It is noticed that although $90.7 \%$ of respondents agreed with the necessity of applying automation and robotics in high-rise building construction, only $18.5 \%$ of their companies had specific plans in their future projects.

The evaluation results of the needs and influential factors are shown in Table 1 and Table 2. The overall mean scores of the needs range from 3.15 to 4.36 , and those of the influential factors range from 3.30 to 4.41 . The top 10 needs and top 10 influential factors were marked with asterisks $(*)$.

Table 3. Profiles of respondents and their companies.

\begin{tabular}{|c|c|c|c|c|c|}
\hline Respondents & $\mathrm{N}$ & $\%$ & Responding Companies & $\mathrm{N}$ & $\%$ \\
\hline Position & & & Company scale (number of employees) & & \\
\hline Chief engineer/deputy chief engineer & 53 & 49.1 & Small ( $<600$ employees $)$ & 16 & 14.8 \\
\hline General manager/deputy general manager & 12 & 11.1 & Medium (600-3000 employees) & 46 & 42.6 \\
\hline Technical director & 31 & 28.7 & Large (>3000 employees) & 46 & 42.6 \\
\hline Others & 12 & 11.1 & & & \\
\hline Work experience & \multicolumn{5}{|c|}{ Have experience of applying the following technologies } \\
\hline$<5$ years & 6 & 5.6 & Building Information Modeling (BIM) & 102 & 94.4 \\
\hline $5-10$ years & 14 & 13.0 & Internet of things (IoT) & 43 & 39.8 \\
\hline $11-15$ years & 7 & 6.5 & Big data & 34 & 31.5 \\
\hline $16-20$ years & 11 & 10.2 & Artificial intelligence (AI) & 26 & 24.1 \\
\hline $21-25$ years & 23 & 21.3 & Automation and robotics & 26 & 24.1 \\
\hline$>25$ years & 47 & 43.5 & & & \\
\hline $\begin{array}{l}\text { Agree with the necessity of applying automation } \\
\text { \& robotics in high-rise building construction }\end{array}$ & 98 & 90.7 & $\begin{array}{l}\text { Have specific plans for applying automation } \\
\text { \& robotics in future projects }\end{array}$ & 20 & 18.5 \\
\hline
\end{tabular}

\section{Development priorities (DPs) and key challenges (KCs)}

To identify DPs and KCs, an international expert workshop was held in November 2018. Thirteen top experts of relevant fields in the world or in China were invited to participate in the workshop, including seven university professors (two from China, two from US, one from Germany, one from Japan, and one from Canada), and six industrial practitioners (three senior engineers from construction companies in China, two specialists from a construction automation software company in China, and one vice president from a robot developer in China). 
In order to ensure smooth communication and discussion, the experts were divided into two groups according to their languages, including an English group (five experts) and a Chinese group (eight experts). In each group, each expert listed top three DPs and top three KCs of automation and robotics in high-rise building construction in the first $30 \mathrm{~min}$, referring but not limited to the lists of top 10 needs and top 10 influential factors received from the questionnaire survey. In the next $60 \mathrm{~min}$, each expert shared ideas about his lists, and other experts discussed the ideas. Finally, the experts spent another $60 \mathrm{~min}$ for further discussion and formed a list of top three DPs and a list of top three KCs. The results are listed in Table 4.

Table 4. Top three DPs and top three KCs proposed by two groups

\begin{tabular}{cllll}
\hline Rank & \multicolumn{1}{c}{ DPs (English group) } & DPs (Chinese group) & KCs (English group) & KCs (Chinese group) \\
\hline 1 & $\begin{array}{l}\text { Protection of work performed } \\
\text { overhead }\end{array}$ & $\begin{array}{l}\text { Prefabricated component } \\
\text { assembly }\end{array}$ & Uncertainty of economic benefit & Immaturity of technology \\
2 & $\begin{array}{l}\text { Monitoring of construction } \\
\text { equipment }\end{array}$ & $\begin{array}{l}\text { Facade construction and } \\
\text { maintenance }\end{array}$ & $\begin{array}{l}\text { Immaturity of technology } \\
\text { Lack of data and analysis on } \\
\text { user demand }\end{array}$ \\
$\begin{array}{l}\text { Steel works (coating, welding, } \\
\text { etc.) }\end{array}$ & $\begin{array}{l}\text { Construction quality } \\
\text { inspection }\end{array}$ & $\begin{array}{l}\text { Incompatibility of existing } \\
\text { application }\end{array}$ & $\begin{array}{l}\text { Incompatibility of existing } \\
\text { construction pattern and robot } \\
\text { application }\end{array}$ \\
\hline
\end{tabular}

The two groups presented six different ideas of DPs in total. In the English group, the top two DPs are both safety issues, respectively focusing on overhead construction work and construction equipment, because robots are expected to conduct safety monitoring and protection jobs for both workers and equipment. Steel works, such as steel coating and welding, received the third position in the English group. Although a large proportion of steel works happen in factories where robots are widely used, others still need to be conducted on site, especially some difficult works for complex joints or components. Researchers and robot developers still have a long way to go from the viewpoint of improving the industrial robots for on-site steel works. In the Chinese group, 'prefabricated component assembly' was ranked top. This echoed the policy of prefabricated building action plan, i.e., improving the proportion of prefabricated building in new building area in China to $15 \%$ by 2020 , which is part of China's 13th Five-Year Plan. Since prefabricated components are more standard, it would be easier for the robots to handle them. The second DP in the Chinese group was 'façade construction and maintenance', which has been a popular research topic of high-rise buildings for over 30 years with various products, and future work is expected to provide more flexible and safe solutions. The third one was 'construction quality inspection', which would be a suitable job for robots because they are efficient in dealing with numerical indicators and always honest with the data. Considering the large volume of quality inspection work, robotics can not only save labor but also reduce the work volume with the selection of appropriate statistical and sampling methods. Besides, robots are capable of inspecting narrow or dangerous locations onsite which are difficult for workers to reach.

As for KCs, the two groups presented four in total, including two same ones and two different ones. The top KC in the English group was 'uncertainty of economic benefit', which is a typical problem appearing in most cases of promoting new technologies. Immaturity of technology received both the second position in the English group and the top position in the Chinese group. Researchers have achieved remarkable successes in construction automation and robotics, but only a few of them are mature enough to be translated into practical use. For the two KCs above, more demo tests should be conducted before application, and small-scale and easy applications would be more acceptable. The third $\mathrm{KC}$ in both the English group and the Chinese group was 'incompatibility of existing construction pattern and robot application', which concerned that the need of applying automation and robotics are not taken into account in the existing designing processes, construction methods and construction organization. To cope with this challenge, the construction phase needs to be re-designed and integrated with the design phase, so that new robots could be developed under a standard framework of integrated design and construction. Another KC in Chinese group was 'lack of data and analysis on user demand', receiving the second position, which indicated that some of existing robotic technologies and products are not exactly fit in with the user demand. A possible reason for this problem is the information access- 
related isolation of different parties. Therefore, all parties need to develop more communication and cooperation so that the researchers and robot developers could grasp the true demands of the construction industry.

\section{Conclusion}

Consistent application of automation and robotics are expected to improve the construction industry in many aspects. Although many efforts have been made in this field over the last three decades, the application rate at the construction sites is still limited. Therefore, this study focused on high-rise buildings, conducted a questionnaire survey and an international expert workshop, investigated and analyzed DPs and KCs, and proposed resulting suggestions. The top DPs include protection of overhead construction work, monitoring of construction equipment, steels works, prefabricated component assembly, façade construction and maintenance, and construction quality inspection. The top KCs include immaturity of technology, incompatibility of existing construction pattern and robot application, uncertainty of economic benefit, and lack of data and analysis on user demand. These findings are expected to be valuable for researchers, robot developers and construction companies to further develop and refine appropriate concepts and apply automation and robotics in high-rise building construction.

\section{Acknowledgments}

The study has been supported by the Tsinghua - Glodon Joint Research Center for Building Information Modeling.

\section{References}

[1] T. Bock, The future of construction automation: Technological disruption and the upcoming ubiquity of robotics, Automation in Construction, 59, 113-121, 2015, https://doi.org/10.1016/j.autcon.2015.07.022.

[2] J. S. Russell, M. J. Skibniewski, An ergonomic analysis framework for construction tasks, Construction Management and Economics, 8(3), 329338, 1990, https://doi.org/10.1080/01446199000000027.

[3] M. J. Skibniewski, C. Hendrickson, Analysis of robotic surface finishing work on construction site, ASCE Journal of Construction Engineering and Management, 114(1), 53-68, 1988, https://doi.org/10.1061/(ASCE)0733-9364(1988)114:1(53).

[4] M. J. Skibniewski, Framework for decision-making on implementing robotics in construction. ASCE Journal of Computing in Civil Engineering, 2(2), 188-201, 1988, https://doi.org/10.1061/(ASCE)0887-3801(1988)2:2(188).

[5] A. Warszawski, R. Navon, Implementation of Robotics in Building: Current Status and Future Prospects, Journal of Construction Engineering and Management, ASCE, 124(1), 31-41, 1998, http://dx.doi.org/10.1061/(ASCE)0733-9364(1998)124:1(31).

[6] T. Bock, T. Linner, Construction Robots: Elementary Technologies and Single-task Construction Robots, Cambridge University Press, New York, USA, 2016, https://doi.org/10.1017/CBO9781139872041.

[7] T. Bock, T. Linner, Site Automation: Automated/Robotics On-site Factories, Cambridge University Press, New York, USA, 2016, https://doi.org/10.1017/CBO9781139872027.

[8] International Association for Automation and Robotics in Construction, Catalog of Robots and Automated Machines, 1998, https://www.iaarc.org/a_publications_IAARC_catalogue.pdf(Accessed March 24, 2019).

[9] S. Cai, Z. Ma, M. Skibniewski, J. Guo, L. Yun, Application of Automation and Robotics Technology in High-Rise Building Construction: An Overview, 35th International Symposium on Automation and Robotics in Construction, Berlin, Germany, July 20-25, 2018, https://doi.org/10.22260/ISARC2018/0044.

[10] S. Lim, R.A. Buswell, T.T. Le, S.A. Austin, A.G. Gibb, T. Thorpe, Developments in construction-scale additive manufacturing processes, Automation in Construction, 21, 262-268, 2012, https://doi.org/10.1016/j.autcon.2011.06.010.

[11] J. Wong, J. Zhang, J. Lee, A vision of the future construction industry of Hong Kong, 32nd International Symposium on Automation and Robotics in Construction and Mining: Connected to the Future, Oulu, Finland, June 15-18, 2015, https://doi.org/10.22260/ISARC2015/0110.

[12] D. Castro-Lacouture, Construction Automation, in Springer Handbook of Automation, Springer Berlin Heidelberg, Berlin, 2009, 1063-1078, https://doi.org/10.1007/978-3-540-78831-7.

[13] K.D. Hampson, J.A. Kraatz, A. Sanchez, The global construction industry and R\&D, in R\&D Investment in the Global Construction Industry, Routledge, 2014, https://doi.org/10.4324/9781315774916.

[14] L. Liao, E.A.L. Teo, S.P. Low, A project management framework for enhanced productivity performance using building information modelling, Construction Economics and Building, 17(3), 1-26, 2017, https://doi.org/10.5130/AJCEB.v17i3.5389.

[15] G. Quezada, A. Bratanova, N. Boughen, S. Hajkowicz, Farsight for construction: Exploratory scenarios for Queensland's construction industr y to 2036, CSIRO, Australia, 2016, http://csq.org.au/csq/media/Common/Knowledge\%20Centre/Knowledge\%20Centre\%20Publications/CSQ Farsight_Report_2016_LR.pdf (Accessed March 24, 2019).

[16] A.M. Blayse, K. Manley, Key influences on construction innovation, Construction Innovation, 4(3), 143-154, 2004, https://doi.org/10.1108/14714170410815060.

[17] B. Khoshnevis, Automated construction by contour crafting — related robotics and information technologies, Automation in Construction, 13(1), 5-19, 2004, https://doi.org/10.1016/j.autcon.2003.08.012. 